\title{
Impending paradoxical embolism: a rare but important diagnosis
}

M E Speechly-Dick, S J Middleton, R A Foale

\begin{abstract}
A man aged 50 presented with a history of a cerebrovascular accident and arterial embolism at two discrete peripheral sites. Echocardiography showed thrombus trapped in an interatrial site and impending paradoxical embolism was diagnosed. Treatment with heparin was started and the potentially embolic intracardiac material was removed at open heart surgery. The patient was treated with warfarin and made a good recovery. This is only the third case report of impending paradoxical embolism diagnosed in life.
\end{abstract}

Impending paradoxical embolism is rarely diagnosed in life. Two previous cases have been reported; one was diagnosed with transoesophageal echocardiography and the other by conventional cross sectional contrast echocardiography. ${ }^{12}$ In both cases the impending embolus was trapped in an interatrial site. Criteria for the anatomical diagnosis were established by Johnson before the introduction of echocardiography. ${ }^{3}$ According to these criteria the diagnosis should be made only when embolic material can be shown at angiography straddling the site of the left to right shunt about the time of systemic embolisation. Johnson, however, also described how a paradoxical embolism could be provisionally diagnosed in the absence of either embolic material straddling the atrial septum or a thrombus seen in the venous system, or the demonstration of an abnormal communication between the right and left circulations. These criteria were clinical, angiographic, or pathological evidence of systemic embolism together with evidence of a favourable pressure gradient for blood flow from the right to left side of the heart. We report a third case of impending paradoxical embolism which illustrates both the variety of the condition and also how easily the diagnosis of paradoxical embolism can be overlooked despite an apparently adequate investigation.

\footnotetext{
St Mary's Hospital, London

M E Speechly-Dick

S J Middleton

R A Foale

Correspondence to

Dr M E Speechly-Dick, Department of Cardiology, The Middlesex Hospital, Mortimer Street, Londo W1N 8AA.
} been an inpatient for one month after his emergency admission with a cerebrovascular accident. Five days before this admission he had presented to an accident and emergency department with a pulseless, cold left foot; this resolved within 24 hours. The day before his admission he had been seen again at a second accident and emergency department with amaurosis fugax and an outpatient appointment had been arranged. He was eventually admitted as an emergency after the development of what was on clinical grounds a large right cerebral infarct in the territory of the middle cerebral artery, with midline shift and oedema confirmed on the computed tomogram.

This patient's past medical history included longstanding pulmonary sarcoid, hypertension, and left ventricular failure. He had smoked heavily until six years before admission. At admission he was taking captopril (25 $\mathrm{mg}$ ), frumil (amiloride hydrochloride $(5 \mathrm{mg}$ ) and frusemide $(40 \mathrm{mg})$ ), and enteric coated prednisolone $(20 \mathrm{mg}$ ) once a day and was using salbutamol and ipratropium nebulisers. There was nothing else of note in his history. Echocardiography was performed two days after admission to exclude a cardiac source of his multiple emboli. This echocardiogram was technically unsatisfactory but was reported to be normal except for the possibility of a small abnormality in the atrial septum, which was of uncertain clinical importance. His clinical course remained uneventful and he was treated with a reducing dose of steroids, subcutaneous heparin, and physiotherapy.

Echocardiography was repeated after four weeks and on this occasion showed an intracardiac mass extending from the left to the right atrium via an atrial septal defect. $\mathrm{He}$ was then transferred to our hospital for further assessment. Repeat echocardiography confirmed the presence of the intracardiac masses (figure). The appearance of the mass was consistent with thrombus. It clearly straddled the interatrial septum and was highly mobile within both atria; during diastole it prolapsed through both atrioventricular valves. Heparin treatment was started and the next day the patient underwent open heart surgery with cardiopulmonary bypass. Organised thrombi were removed from both atria and the stretched foramen ovale was closed. These intracardiac masses were confirmed to be thrombi on histological examination and were sterile on culture. Because they looked like venous casts, it seemed likely that they had originated in the deep veins of the legs. The patient made an uneventful postoperative recovery. He continues to be treated with warfarin, which was started postoperatively, and with rehabilitation his mobility and independence are improving. 
A subcostal four chamber echocardiogram showing a mobile thrombus straddling the interatrial septum and lying within left and right atria. IVS, interventricular septum; $L A$, left atrium; $L V$, left ventricle; $R A$, right atrium; $R V$, right ventricle.
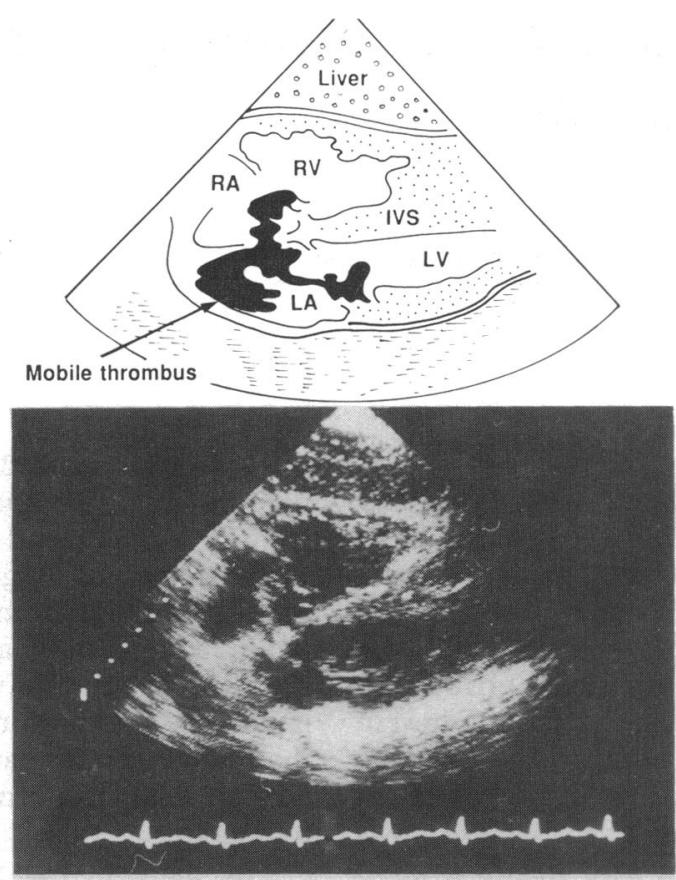

\section{Discussion}

Paradoxical embolism is a well recognised complication of a right to left communication which is usually diagnosed at necropsy. We know of 37 reported cases ${ }^{124}$ of which only two were diagnosed in life. A deep venous thrombosis can give rise to pulmonary emboli which cause an increase in right atrial pressure. If there is a primitive communication between the atria, for example a frank atrial septal defect or incompletely fused fossa ovalis, the rise in right atrial pressure allows thrombus to cross into the systemic circulation and may give rise to paradoxical arterial embolisation.

A review of the features surrounding the event of paradoxical embolism showed that $60 \%$ of paradoxical emboli occur at the onset of symptoms of pulmonary embolism, probably because the resultant increase in right atrial pressure opens the unfused fossa ovalis and therefore the right to left shunt. ${ }^{4}$ Fifteen per cent of paradoxical emboli seem to occur during a manoeuvre that raises right heart pressure and $5 \%$ occur against a background of chronically raised right heart pressure. ${ }^{247} \mathrm{~A}$ necropsy review by Loscalzo of 30 patients with paradoxical embolism showed that most had a patent foramen ovale, a relatively common anatomical abnormality; in only a few was the right to left shunt caused by an atrial septal defect. ${ }^{2}$ This reported incidence of a patent foramen ovale was confirmed by other reports ${ }^{47}$ About a third of Loscalzo's patients had two or more defined embolic sites as did our patient; in $37 \%$ of patients these were primarily cerebral.

We diagnosed impending paradoxical embolism in our patient on the basis of Johnson's original criteria but with conventional echocardiography as the imaging method. Subtle interatrial connections are better visualised by transoesophageal echocardiography. ${ }^{28}$ None the less, the potential for a right to left shunt can be demonstrated by contrast echocardiography and manoeuvres that raise right sided pressures (such as the Valsalva manoeuvre).

Patients with systemic emboli and a clot in the right atrium shown by conventional echocardiography are at a high risk of paradoxical embolism developing and require urgent treatment. In our patient echocardiography showed a thrombus straddling an interatrial communication and review of the echocardiographic data suggested that this thrombus was present at the time of first echocardiographic examination and that it gave rise to the patient's systemic emboli.

In two groups of patients the likelihood of paradoxical emboli is high: (a) those who have venous thrombosis or pulmonary embolism associated with systemic arterial embolisation; and $(b)$ those with arterial embolisation with no obvious evidence of a left sided cardiac source. Patients in either of these groups should be investigated with cross sectional contrast echocardiography; if this does not detect a right to left shunt, transoesophageal contrast echocardiography should be used. The aetiology of the embolus in embolic stroke is undetermined in approximately $36 \%$ of patients ${ }^{9}$; a considerable proportion of these may be a consequence of paradoxical embolisation.

When a paradoxical embolism is diagnosed, measures should be taken to prevent a recurrence. Treatment has included anticoagulation $^{12410}$ to prevent the formation of further venous emboli, interruption of the inferior vena cava, ${ }^{11}$ and surgery to close the right to left shunt and remove intracardiac thrombus. ${ }^{12}$ In our patient we elected to remove the potentially embolic intracardiac material at open heart surgery on cardiopulmonary bypass and to close the patent foramen ovale. Obviously we cannot compare these treatments but a review of published reports suggests the following treatment strategies. All patients should be anticoagulated unless this is contraindicatedfor example, by a haemorrhagic cerebrovascular accident. The optimum length of time of anticoagulation is not known but should be indefinite if there is an underlying untreated cause of venous thrombosis. Peripheral emboli should be treated by embolectomy or thrombolysis as indicated. Ligation of the vena cava cannot be recommended because of considerable mortality and high recurrence rates. ${ }^{12}$ The cardiac defect is most commonly a patent foramen ovale, which should remain closed when the right atrial and other right heart pressures are normal; under these circumstances surgical correction is not indicated for paradoxical embolism.

Paradoxical embolism may be more common than is currently thought. ${ }^{11}$ The diagnosis should be considered whenever arterial embolisation has no obvious cause. Echocardiography should be performed to determine whether a right to left shunt is present, and venous thrombosis should be excluded. Correct diagnosis allows prompt treatment to be given and may prevent further catastrophic emboli. 
1 Nellesen U, Daniel WG, Matheis G, Oelert H, Depping K Lichtlen P. Impending paradoxical embolism from atria thrombus: correct diagnosis by transoesophageal echocar diography and prevention by surgery. $\mathrm{J} \mathrm{Am} \mathrm{Coll} \mathrm{Cardiol}$ 1985;5:1002-4.

2 Loscalzo J. Paradoxical embolism: clinical presentation, diagnostic strategies, and therapeutic options. Am Heart 1986;112:141-4.

3 Johnson BI. Paradoxical embolism. J Clin Pathol 1951; 4:316-32.

4 Leonard RC, Neville E, Hall RJ. Paradoxical embolism. A review of cases diagnosed during life. Eur Heart $J$ 1982;3:362-70.

5 Laughlin RA, Mandel RS. Paradoxical embolisation. Case report and review of the literature. Arch Surg 1977; 112:648-50.

6 Achim J, Erbel R, Darius H, Rumpelt H, Meyer J. Paradoxical coronary embolism. Case report and review of literature. Am Heart J 1988;116:879-85.
7 Lang I, Steurer G', Weissel M, Burghuber OC. Recurrent paradoxical embolism complicating severe thromboembolic pulmonary hypertension. Eur Heart J 1988;9: 678-81.

8 Schlüter M, Langenstein BA, Polster J, et al. Transoesophageal cross-sectional echocardiography with a phrased array transducer system. Technique and initial clinical results. Br Heart J 1982;48:67-72.

9 Caplan LR, Hier DB, D'Cruz I. Cerebral embolism in the Michael Reese Stroke Registry. Stroke 1983;14: $530-6$.

10 Leonard RC, Neville F, Hall RJ. Paradoxical embolism associated with patent foramen ovale. Postgrad Med J 1981;57:717-8.

11 Meister SC, Grossman W, Dexter L, Dalen JE. Paradoxical embolism. Am J Med 1972;53:292-8.

12 Nabseth DC, Moran JM. Re-assessment of the role of inferior vena cava ligation in venous thromboembolisation. N Engl J Med 1965;273:1250-3.

\section{PLANTS IN CARDIOLOGY}

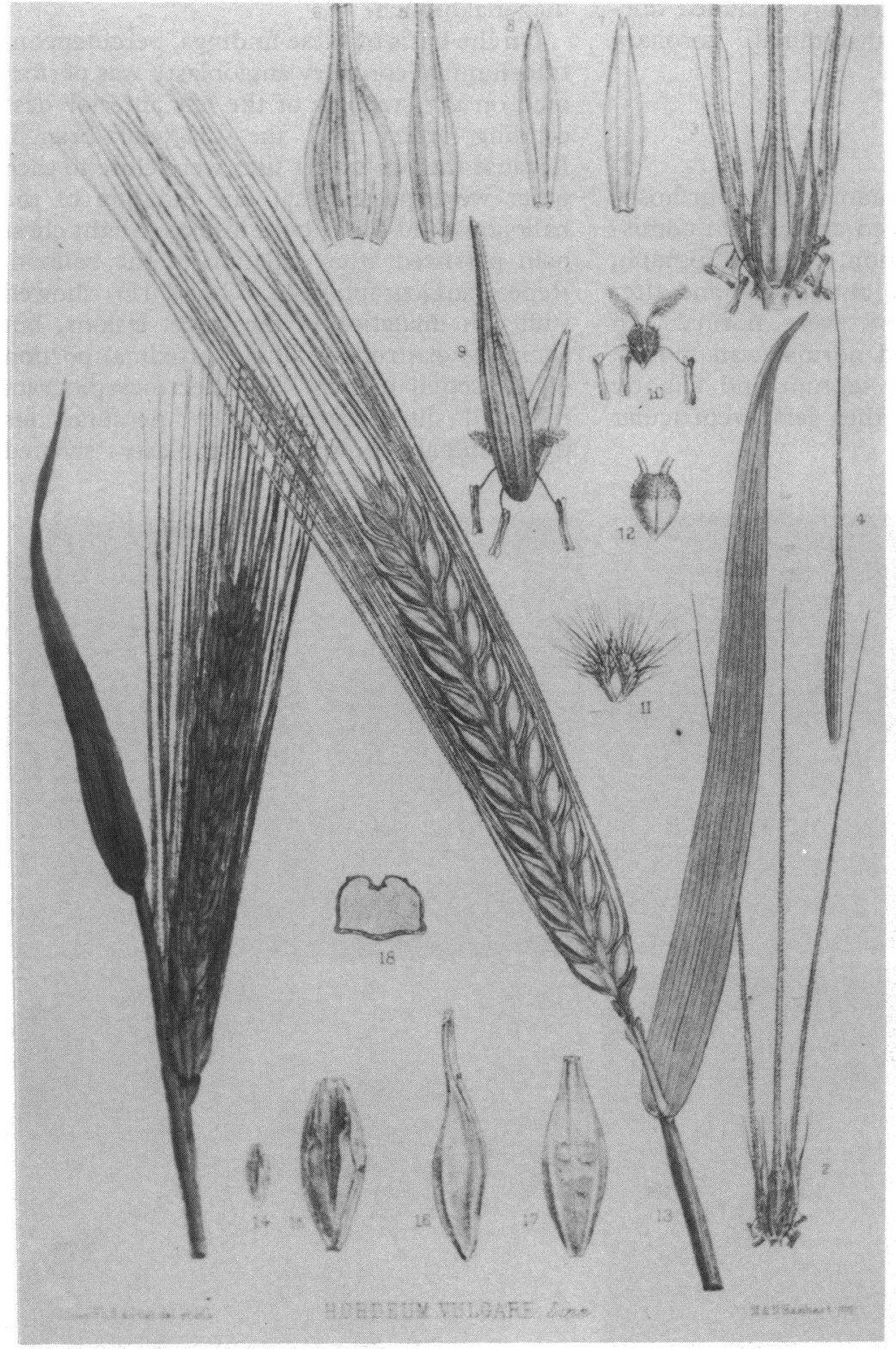

Hordeum vulgare L. Bentley R, Trimen H. Medicinal plants. Vol 4. London: Churchill, 1880:293.

\section{Lignocaine}

In 1932 Professor Hans von Euler pioneered a new concept when he sought chemical differences between genetically different types of plant. For his first study he chose a chlorophyll defective mutant of barley, Hordeum vulgare, and isolated a compound $\mathrm{C}_{11} \mathrm{H}_{14} \mathrm{~N}_{2}$ which was not present in normal barley, or in other green plants that he tested. He called the compound gramine after the plant's family Gramineae and he thought that it was 2-(dimethylaminomethyl)-indole. But when his assistant Holger Erdtman synthesised this compound in 1935 it proved to be isogramine not gramine, which is 3-(dimethylaminomethyl)-indole. When Erdtman tasted the isogramine he found that it anaesthetised his tongue which gramine did not. But isogramine was too irritant to use as a local anaesthetic and although Erdtman and Nils Lofgren with the support of Astra synthesised several analogues they also could not be used clinically.

The work then stopped for some years but Lofgren later resumed the project, again with Astra's support and in 1943 he produced Xylocaine, which after extensive testing was marketed in 1948. Its generic names are lignocaine and lidocaine.

Gramine was, however, also isolated by Russian workers in 1935 from the great reed Arundo donax L. This plant claimed attention because camels refused to eat it because of its bitter taste.

R DAHLBOM A HOLLMAN 